\title{
Pedagogical opportunities to improve training system on the basis of advanced foreign experience
}

\author{
A.J.Turekeeva ${ }^{1}$ \\ Base doctoral student, Nukus state pedagogical institute named after Ajiniyaz, Nukus, Uzbekistan \\ E-mail: turekeeva_a@umail.uz
}

\begin{abstract}
The article describes the current stage organizing methods' study of education system development of the Republic of Uzbekistan, intensification and the modernization process general direction, professional development of the public education system staff, foreign and domestic technologies experience and teachers' professional development in the additional vocational education system in accordance with the theoretical literature the need to improve the continuous vocational education system, as well as vocational education programs in general, technology, teaching methods and forms' development and modernization for adults.
\end{abstract}

Keywords: education system, public education system staff, professional development, continuing professional education system, component, professional activity, professional knowledge, audience, modern teacher.

\section{Introduction}

The current development stage of the education system of the Republic of Uzbekistan is characterized by the modernization process intensification and the systemic changes in the general direction. These changes purpose is to adapt the educational process to the modern real life requirements, to create new, modern mechanisms for regular educational process updating, to identify the individual, society, state needs to choose the current and future path. Such modernization basic tasks implementation of basic innovative nature education requires an individual and differentiated approach to each trainee in the state requirements implementation applied in the professional development system.

Hence, the modern training system task, which is the most important modernization and innovative development component, is to cultivate a mature specialist who is able to independently choose the individual development trajectory in a high-tech competitive environment, taking into account each trainee needs.

The rapid development pace includes significant changes and innovations in the professional development process about the students' professional activities in the assessment tools implementation for students' scientific achievements, teaching methods, organizational forms and other methods of teaching. Therefore, in the professional development process, special attention should be paid to the trainees' professional knowledge, skills and competencies level and their professional activities implementation. To do this, it is necessary to "... raise the status and prestige of the teaching profession, provide material and social support to general education institutions employees, as well as the public education system, create appropriate conditions for their effective work $^{1 " .}$.

In the professional development process, students should be able to give a stable impetus to the learning process as studentsэ pedagogical, psychological and acmeological observation result, reveal the knowledge meaning learned by students, learn new goal setting technologies and apply them in educational practice. This is especially important to ensure their activities success in the audience. At the same time, it is important that teachers not only teach students to know or memorize what they have read in a particular subject, but also to form in them the competencies to apply what they have learned in real-life situations.

It should be noted that enriching the teachers' didactic, methodological, methodological and philosophical views with an average 45-50 age in the country, training them to perform the tasks set by the new educational standards is the weakest training system point today. To prevent this vulnerability, it is necessary to change all curricula and programs content, updated on the state requirements, qualification requirements basis, created for the advanced training system. Thus, it is not a task for listeners to work in a simple biblical knowledge paradigm, but for them to move to a "knowledge-based practical" approach in the professional development process.

\section{Materials and methods}

Taking into account the above, the in-service training system is a modern requirement for the modern teachers' professional development, a radical reform of the in-service training system. The professional development process is a multifaceted, complex process that covers all education system components, and any changes in the education system are synchronized with the teachers activities who are the subjects, the educational process executors.

It should not be forgotten that the backwardness and the society socio-economic and spiritual-moral development vulnerability depends on the education quality and its outcome. These problems solution promotes the ongoing ideas to improve the teachers' skills in the education, their professional retraining and certification system modernization field. These ideas are aimed at solving the necessary conditions and tasks for the educational process' organization and implementation, aimed at the additional training programs

${ }^{1}$ The President Resolution of the Republic of Uzbekistan on September 5, 2018 PR№-3931 "On measures to introduce new principles of governance in the public education system" 
individualization for students. The main creating source of these conditions is considered to be a system based on teacher self-development in the continuing education system, their own individual educational program development and implementation.

The educational process organization peculiarity in the professional development system is aimed at ensuring the students' holistic professional skills development. This is confirmed by the trainees rating results of advanced training courses.

In conversations with the audience, it became clear that they consider the advanced trainings effectiveness conducted during the theoretical training to be lower than that independent training. In addition, while $40 \%$ trainees submitted proposals for in-service training at least once a year, $60 \%$ of them prefer practical training. This is due to the fact that the most common professional development method in the past was not to improve the real audience's professional skills, but to use more new technologies in practical training. For this reason, it is often the case that professors increase their professional knowledge through students' self-teaching in the practical training course. The current teacher training system in the public education system is focused on their mutual traditional experiences study, rather than on the various innovations that students face in the teaching environment. At the same time, the innovation level in the learning process does not always correspond to the students abilities in real working conditions. Therefore, the main professional development purpose for today's employees public education system is to provide students with new pedagogical and ICT innovations in their specialties, to absorb innovations in the educational process using advanced foreign experience.

Our task in this area is to work tirelessly on ourselves in these processes organization, to study in depth a particular foreign language in order to apply advanced foreign experience in educational practice.

Thus, the teacher must have a sufficiently high qualification in self-teaching field as a core subject designed to address the education problems developmental. At present, the "modern image of the teacher" definition and the optimal conditions for its professional development should be one of the most urgent tasks of the Ministry of public education.

The defining problem the professional development essence of a modern teacher is currently causing controversy and disagreement among psychologists, practitioners, specialists, teachers. Including researches by Yu.Asadov, M.Yuldashev, A.Ibragimov, A.A.Andreev, S.A.Dochkin, V.D.Shadrikov, D.Kucher, D.B.Khogan, R.Meyers, V.Blank, Dj.Eliot, and Dj.Ravens.

However, in many cases, scholars have taken into account the professional qualities of teachers, the conditions under which they are formed and evaluated.

Thus, how does the "master" of his profession differ from other educators, that is, as a professionally developed person with high pedagogical and psychological qualifications. It also remains an open question about the leading trends and mechanisms for the professional development of the modern teacher. Comprehensive approaches analysis to shaping the teacher training process content organization, various author's pedagogical structures, teacher training concepts, organizational training programs for qualified professionals, programs identification that provide teachers with the necessary professional skills, sustainable teacher training the motivation formation for the teacher to gain professional and personal experience in their own individual curriculum development and implementation, in our opinion, is not fully covered in the modern scientific literature.

Thus, the theory and practice analysis of teacher professional development in the additional professional education context allows to distinguish between the following:

the need in a modern school for a teacher who can competently organize and cooperate with students in the individual curricula implementation, and in this regard, the lack of teachers' professional development;

the objective necessity of teachers' specially organized professional development, the lack of conditions' theoretical model development for ensuring a high individualization and teachers' professional development level.

\section{Main part}

Thus, the research problem is the need to create and test the organizational and pedagogical conditions that ensure their development in the teachers' professional development process. Theoretical and practicalmethodological bases of the research are:

essence defining areas of professional maturity: activity based on a specific task;

personal activity;

the adult education concept;

the continuous professional development and teacher self-development concept;

the competent approach concept to the learning process;

the problem-based learning concept;

the learning process accelerating and improving concept.

The new directions essence in the in-service training development is determined by a number of documents ratified by the state. This will help our country to enter the world education system and stimulate an integrated educational process. At the same time, there is a convergence process and education systems harmonization in different countries. Here:

high-level training availability and advanced training; 
academic mobility, i.e. the opportunities availability for experience exchange;

access availability to credit units.

Today, not only in our country, but all over the world, the field of education is being renewed on the basis of nanotechnologies, radical reforms are being carried out in the field of education. There is an opportunity for professionals to monitor the development of the world education system, to take into account existing markets, to identify and design a new economy.

The relationship analysis between the current economy and the education system problems is the state and society development guarantee. Such changes are also very important for the professional development system of public educators.

The state educational standards introduction, which is a pressing issue for teachers today, should include changes in their professional activities, first of all, the territorial and regulatory component of the educational process, teaching methods, learning outcomes and assessment tools, the regulatory framework of the educational process.

In the professional development process it is possible to discuss the teachers' activities features of general secondary schools in the SES implementation framework. According to the teachers' qualification descriptions: conducts research on the achievements basis in various forms, methods, techniques, teaching and methodological manuals, modern educational and information technologies, digital educational resources, pedagogy and psychology, developmental psychology and school hygiene. They also organize modern information technologies and teaching methods, students' independent activities, ensure the theory and practice unity, discuss relevant modern activities.

Teachers develop information, improve teachers' skills and abilities, develop creative experience, evaluate the effectiveness and learning lessons outcomes (SES, program), taking into account the knowledge and students' interests using computer technology, modern assessment methods in terms of information and communication technologies (electronic documents and electronic journals) use, monitoring and evaluation activities in the learning process.

Today, the modern education system is faced with finding answer task to the question "What should a modern teacher be like?" Standardization and modernization of the pedagogical education system in general is aimed at solving this problem. Specialists in the in-service training system are working on this problem. This topic is most discussed in national and foreign scientific journals. Any change effectiveness in the education system of all participants in these discussions depends on the teacher as these changes exact executor. However, the predetermined the above-mentioned innovations introduction level in education does not always correspond to the teacher capabilities. To perform such tasks, a teacher must be sufficiently highly qualified.

S.A. Dochkin noted that the current education system conditions, its structural and substantive reforms lead to overcoming the psychological difficulties associated with the intellectual and emotional professional activity stress of the teacher. In addition, the modern teaching practice development determines the new content emergence and professional pedagogical activity characteristics. In this regard, in the modern implementation and topical professional activity tasks, many teachers face the problem of not knowing enough about the current and basic professional competencies in the form in which they are increasingly interpreted. As a result, the teacher is experiencing a professional competence crisis. According to recent research in this area, the following main causes of teachers' professional competence crisis in general education institutions can be considered. Including:

changes in important social development priorities, rapid social consciousness change and professional consciousness rigidity, experts opinions (pedagogical conservatism as a deformation), directing most of them to traditional means, methods, of solving professional tasks techniques;

the lack of teachers' majority ideas about the best pedagogical skills examples, the achievements use of the world pedagogical community in teaching practice;

the teachers' role in the teachers' training and retraining system.

As a result, the teachers' personal-professional deformation risk increases. These include teachers 'anxiety, nervousness, tension, high aggression levels, internal uncertainty, decreased non-professional activity, lack of empathy, humility, and demonstration.

According to N.B. Moskvin, almost each of these characteristics represents one of the possible development tasks of professionally important tasks of the modern teacher. In other words, the important qualities development increases the pedagogical work effectiveness in teachers. It should be noted that the occurrence establishment of deformation is a probabilistic feature, i.e. it is one of the important teacher professional development areas.

In addition, the teacher's self-training, his didactic, methodological, philosophical point formation of view is determined by the SES weakest part implementation, which determines the current professional pedagogical activity content. This content involves the developing environment creation in the educational institution, a qualitatively new system of student assessment, the modern educational technologies use, education methods and forms, the competency-based approach implementation to learning, friendly subject-subject relations and more.

In our opinion, what is new and special in terms of normative documents regulating the teacher activities 
in this situation allows the student to choose the curriculum that is related to the individual curriculum formation.

The teacher contributes to the formation, socialization, proper selection and development of the individual culture of the individual, using accelerated courses within the various forms of SES, methods, teaching aids, including individual curricula.

There is no doubt that today the teacher accompanies the student in mastering the selected curriculum content using various forms, methods, techniques and tools. An entirely new task for the teacher is to form the students ability to consciously choose educational programs, that is, to create individual curricula. Thus, the teacher tries to be the objective knowledge possessor that the student is trying to impart to them. In other words, the teacher moves from the educator position to the mentor position.

In this process, the main student's task is to form a knowledge in which students have a conscious attitude to learning, a stable motivation to show initiative, independence in discovering new knowledge, ways to apply this knowledge in solving various problems.

A key feature of the national education system during the teacher training period was the didactic-centric approach. Training based on the rapid information presentation involves the specific knowledge, skills and practical competencies transfer.

In the knowledge-based paradigm context, the learner's task was primarily to learn what was given and to repeat it under control. Such activity in the educational process acquires a reproductive character with its content and direction. This is what defined the memory priority, and not enough attention was paid to the managed reflexive skills, self-management, creative, critical thinking, etc. development, which are only indirectly realized.

In addition, these teachers do not have the experience to create an individual curriculum, as their training is provided in curricula that predetermine strict development directions.

After graduating from a higher education institution, they repeat their knowledge in the bachelor's degree in the teacher's training system. Thus, the teachers' preparation for advanced education programs that include traditional teaching methods and a single invariant content for the whole students group is done once every five years. No attention has been paid to the reflexive skills formation, the ability to build a professional development trajectory, taking into account their own difficulties and shortcomings in the educational process.

It should be noted that the long interaction period, the schools and teachers' practice on single methodological topics did not contribute to the effective professional development of teachers. Therefore, today the task for the teacher is to move from a knowledge-based approach to a competency-based system.

Thus, the teachers' preparing task to perform qualitatively new functions within the SES implementation framework is carried out, first of all, by modernizing the professional development system. This plan priority is to identify the requirements for the educational process' organization and implementation aimed at the additional vocational education programs individualization. One of the measures to accomplish this task is to include information about the training modules and the mechanisms for their implementation in the data module in the monitoring automated teachers' the professional development system. To implement a competency-based approach, the more than 168 training modules content was analyzed in the following areas for general education system teachers to study the curriculum modules to individualize the training process. Including: history, sociology, law and economics; primary general education; social sciences and humanities; exact and natural sciences; correctional pedagogy and special psychology.

As a result, we believe that the curriculum programs content mainly reflects the generalized experience in a particular structures area that implement these programs, but does not provide individualization, a competent approach in the advanced learning process is designed to prepare the teacher to perform real professional tasks. The need to overcome the above challenges and contradictions requires the processes study and mechanisms for the certain necessary competencies development of teachers to ensure effective pedagogical activity, daily activities and adaptability in modern society.

The solutions to the problems of teacher professional development presented in a number of studies on pedagogy are based on general ideas about the development process as the individual formation in social manifestations under the internal motives and external factors influence: social, economic, axiological, pedagogical, psychological, etc. The result is the professional and personal qualities stability, the certain professional maturity attainment. It should be noted that the development process is associated with stimulating and activating processes the creativity process, meaningful learning, self-development and self-learning.

The development process effectiveness is determined by different individual characteristics. Competency development takes place throughout the entire career development path, so the professional competencies descriptions are incomplete and a constant dynamic. It is also a managed professional development process, which takes place through teacher training and self-education, an impact process that provides a specific standard that serves as a starting point for the exposure subject.

As G. Boymuradova and S.A. Dochkin noted, professional competence is dynamic, but it is not some frozen powers set. This reveals a development trend. In turn, the individual competencies formation or improvement should be considered as an integral part of the overall development process of professional pedagogical competence, during which specially organized changes are made in the professional competence structure of the teacher and its manifestation [2; 26-30]. 
The new qualitative aspects basis of the teacher should be the self-management process, that is, the teacher's internal qualifications, professionalism level, the teacher's independent action rises to a more perfect level than the initial level. Given that the teacher's professional skills include targeted internal or external influences rather than spontaneous, the professional development system priorities today are to design this process models, develop its operating technologies, mechanisms and algorithms, improve organizational tools and methods, - methodological support needs to be improved.

The media creation, operation, and development to nurture a highly competent teacher can be an external aspect of this process. Such an environment is a teacher's training and professional retraining system, as its main task is to develop and implement effective forms of teacher professional development.

In accordance with the analyzed theoretical literature, we studied the foreign and domestic technologies experience and teacher training organizing methods in the additional vocational education system (M.Yuldashev, G.Boymurodova, A.Ibragimov, A.Ibraymov, P.Jarvis, M.Noulz, X.Sakamoto, Ya.Gibson, D.Allen, V.Blank, A.Shmidt, A.I.Juk, C.Ya.Batyshev, E.F.Zeer, V.P.Bespalko, I.A.Kolesnikova, P.I.Tretyakov, A.V.Khutorskoy and etc.).

The analyzed literature notes that there are a number of problems in this area. These include: the need to improve the continuing vocational education system, as well as vocational education programs and technologies in general, the teaching methods and forms development and modernization for adults;

Currently, practical work is being done to intensify the work on the new methods search and introduction of training students in advanced training institutions. In particular, the portfolio creation, the methodological work consolidation created by students, the programs development for the advanced pedagogical experience absorption, the transition to a modular-credit system, etc.; new forms introduction of education, including master classes, case classes, methodological developments in the advanced training system, seminars organization, webinars for the experience exchange, virtual methodical cabinets creation as an interaction form of resource users in the network, round tables, video conferences, field trips, internships, scientific and methodological advice creation, project, qualification work and other methodological developments, distance learning, etc.

Nevertheless, the additional professional development programs being implemented today are distinguished by their traditional specificity and are the only program for new educational technologies. This makes it difficult to consistently and comprehensively address the effective development ensuring tasks of professional and pedagogical competence. It is worth noting that teachers themselves consider the learning process in the organized system of in-service training (pedagogical skills schools, advanced training institutes, theoretical and methodological seminars, etc.) more inefficient than independent work. This can be explained by the fact that the most advanced, most common professional development forms are not focused on pedagogical skills, but on improving academic degrees. Therefore, in most cases, educators go to increase their professional competencies through independent learning in the practical activities process.

Of course, the self-education importance and self-development in the teacher training process as well as in its professional development should not be overlooked. In both cases, the end result depends in many ways on conscious, purposeful, cognitive, independent activity. Nevertheless, today there are enough educational technologies for adults that allow students to make effective well-organized independent work use to achieve specific learning goals.

It should be noted that taking into account all the changes in the teacher training system can not be considered effective, because:

the professional skills' initial level, the teacher's personal potential is not always taken into account in the learning process;

the program content of the courses is not aimed at improving and developing the teachers' skills;

the technological component of the learning process is distinguished by traditional forms, methods and techniques;

subject-subject relations, competent approaches are not implemented to the required extent;

there is no psychological system and acmeological trainees support, a monitoring system the content and in-service effectiveness training and teachers' different categories retraining;

the scientific mechanism and teachers' methodological support does not work clearly;

there are no technological systems and organizational models for teacher training and the functioning of the vocational retraining system in the form of distance learning, taking into account their diverse and multilevel needs for additional vocational training.

In addition, at the current stage of development of the education system, the paradigm of "lifelong learning" and the transition from periodic professional development of teachers to continuous continuing education are very important. Teachers themselves take a similar view.

The survey results of listeners show that $70 \%$ respondents suggested to organize advanced training courses at least once a year. L.V.Abdalina emphasizes that the multi-purpose nature of the teacher training process and related tasks should take into account the current teacher's professional skills and his abilities, pay special attention to the training's end result, identify and take into account factors and conditions that contribute to professional development. Adequate pedagogical, psychological, acmeological, technological support of this process will allow to achieve efficiency in the educational process. 
According to G.Boymuradova, A.Ibragimov, L.V. Abdalina, the main tasks of the training process are: listeners' professional competence and its components enrichment;

a positive attitude formation to innovative activity and motivation for professional development;

psychological reshaping, professional values renewal;

ensuring the teacher's subjective perspective and social and professional self-development;

developing emotional self-management skills;

mastering the mechanisms and self-development algorithms and management;

psychological barriers to professional development and professional conflicts prevention.

Thus, the system importance of additional professional development education is that it is necessary to diagnose the real teacher's professional skills development, its development prospects, constantly monitor this development, introduce technology developed specifically for the individual formation of the teacher.

Therefore, the current system priorities of professional development are to design conditions models in which the teacher has the competence in the personal qualities field, the ability to develop behavior, competencies in developing an action plan, setting curriculum goals, successful and continuous skills development. Competences in providing an information base that allows for the organization and activities implementation should be reflected in the individual curriculum.

Modern trends in development, normative the professional development system support lead to significant changes in the teachers' professional activities, primarily in the learning process, the content and teaching methods, tools for evaluating students' educational institutions, and so on. The rapid renewal of scientific knowledge and the previous professional knowledge obsolescence, as well as the continuous improvement of skills, require the teachers' involvement in the continuing education process.

Scholars have stated that consideration of the content of professional and pedagogical activity is a prerequisite for radical reform of the entire education system.

Among the transition problems to the new educational standards generation, T.A. Kaplunovich noted the need to include in the learning outcomes list, a key competencies set, specific features identification of competency-oriented curricula and extracurricular programs, setting requirements for educational technologies and interaction methods between the educational process subjects, aimed at the core competencies development $[1 ; 88]$. The author emphasizes the need for these problems' serious scientific understanding, their experimental modeling, these models' professional and public examination, their special organization implementation in educational practice.

\section{Conclusion}

We agree with T.A. Kaplunovich that these tasks can be very complex and that teachers working in the "knowledge" paradigm usually identify the children and groups studied. It also aims to assess whether control materials and teacher certification criteria have been studied. In addition, attention should be paid to creating conditions for the students' individual curricula implementation in educational institutions. These tasks solution, in our opinion, is possible due to the competency-based approach implementation and primarily in the professional development system, where experience-based models of organizational and pedagogical conditions for teacher training can be effectively built.

\section{References:}

1. Noskov I.A. Organizational and pedagogical foundations of an individualized system of professional development of teachers: dis. for doc. ped. sciences. - Moscow, 2002.

2. Boymurodova G.T. Continuous professional development system in modern education // Modern education. - 2014. - № 2. 